\title{
Resolution of High-Frequency Mesoscale Intracortical Maps Using the Genetically Encoded Glutamate Sensor iGluSnFR
}

\author{
Yicheng Xie, ${ }^{1,2}$ Allen W. Chan, ${ }^{1,2}$ Alexander McGirr, ${ }^{1,2}$ Songchao Xue, ${ }^{1,2}$ Dongsheng Xiao, ${ }^{1,2}$ Hongkui Zeng, ${ }^{3}$ \\ and Timothy H. Murphy ${ }^{1,2}$ \\ ${ }^{1}$ Department of Psychiatry, Kinsmen Laboratory of Neurological Research, and ${ }^{2}$ Brain Research Centre, University of British Columbia, Vancouver, British \\ Columbia V6T 1Z3, Canada, and ${ }^{3}$ Allen Institute for Brain Science, Seattle, Washington 98109
}

Wide-field-of-view mesoscopic cortical imaging with genetically encoded sensors enables decoding of regional activity and connectivity in anesthetized and behaving mice; however, the kinetics of most genetically encoded sensors can be suboptimal for in vivo characterization of frequency bands higher than 1-3 Hz. Furthermore, existing sensors, in particular those that measure calcium (genetically encoded calcium indicators; GECIs), largely monitor suprathreshold activity. Using a genetically encoded sensor of extracellular glutamate and in vivo mesoscopic imaging, we demonstrate rapid kinetics of virally transduced or transgenically expressed glutamate-sensing fluorescent reporter iGluSnFR. In both awake and anesthetized mice, we imaged an $8 \times 8 \mathrm{~mm}$ field of view through an intact transparent skull preparation. iGluSnFR revealed cortical representation of sensory stimuli with rapid kinetics that were also reflected in correlation maps of spontaneous cortical activities at frequencies up to the alpha band $(8-12 \mathrm{~Hz})$. iGluSnFR resolved temporal features of sensory processing such as an intracortical reverberation during the processing of visual stimuli. The kinetics of iGluSnFR for reporting regional cortical signals were more rapid than those for Emx-GCaMP3 and GCaMP6s and comparable to the temporal responses seen with RH1692 voltage sensitive dye (VSD), with similar signal amplitude. Regional cortical connectivity detected by iGluSnFR in spontaneous brain activity identified functional circuits consistent with maps generated from GCaMP3 mice, GCaMP6s mice, or VSD sensors. Viral and transgenic iGluSnFR tools have potential utility in normal physiology, as well as neurologic and psychiatric pathologies in which abnormalities in glutamatergic signaling are implicated.

Key words: calcium; cortex; glutamate; in vivo imaging; membrane potential; optogenetic

Significance Statement

We have characterized the usage of virally transduced or transgenically expressed extracellular glutamate sensor iGluSnFR to perform wide-field-of-view mesoscopic imaging of cortex in both anesthetized and awake mice. Probes for neurotransmitter concentration enable monitoring of brain activity and provide a more direct measure of regional functional activity that is less dependent on nonlinearities associated with voltage-gated ion channels. We demonstrate functional maps of extracellular glutamate concentration and that this sensor has rapid kinetics that enable reporting high-frequency signaling. This imaging strategy has utility in normal physiology and pathologies in which altered glutamatergic signaling is observed. Moreover, we provide comparisons between iGluSnFR and genetically encoded calcium indicators and voltage-sensitive dyes.

\section{Introduction}

One of the goals in neurophysiology is to acquire in vivo real-time measures of ongoing neuronal activity (Knöpfel et al., 2006; Akemann et al., 2010; Huber et al., 2012; Tian et al., 2012; Chen et al., 2013b; Stroh et al., 2013; Madisen et al., 2015). When making

Received July 13, 2015; revised Dec. 3, 2015; accepted Dec. 10, 2015.

Author contributions: Y.X. and T.H.M. designed research; Y.X., A.W.C., A.M., and D.X. performed research; H.Z. contributed unpublished reagents/analytic tools; Y.X. and S.X. analyzed data; Y.X. and T.H.M. wrote the paper.

This work was supported by a Canadian Institutes of Health Research (CIHR Operating Grant MOP-12675 to T.H.M.) and the Heart and Stroke Foundation of Canada (Grant in Aid). Y.X. holds a CIHR Vanier Canada Graduate Scholarship and a four-year fellowship from the University of British Columbia. We thank the Allen Institute for Ai85 iGluSnFR transgenic mice; Jonathan S. Marvin for the iGluSnFR construct; Loren Looger and HHMI Janelia Farm for such measurements, one needs to be aware of potential limitations in monitoring approaches. Currently, the standard for electrophysiological assessment is the measurement of transmembrane voltage using an intracellular electrode or extracellu-

generating and making iGluSnFR reagents available; Cindy Jiang and Pumin Wang for assistance with surgical preparations; Jeff LeDue and Jamie Boyd for technical assistance; and Matthieu Vanni and Diana H. Lim for helpful discussions and comments on the manuscript.

The authors declare no competing financial interests.

Correspondence should be addressed to Timothy H. Murphy, Department of Psychiatry, Kinsmen Laboratory of Neurological Research, University of British Columbia, 2255 Wesbrook Mall, Detwiller Pavilion Rm. 4N1, Vancouver, BC V6T 123, Canada. E-mail: thmurphy@mail.ubc.ca.

D0I:10.1523/JNEUROSCI.2744-15.2016

Copyright $\odot 2016$ the authors $\quad 0270-6474 / 16 / 361261-12 \$ 15.00 / 0$ 
A

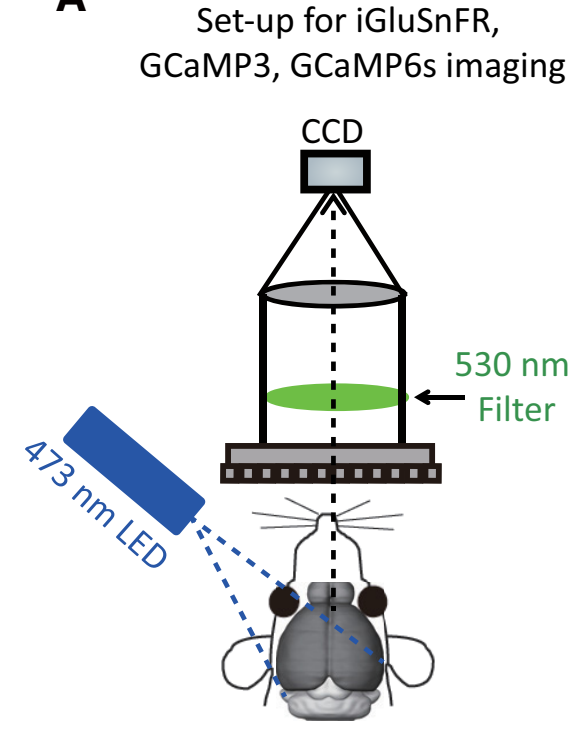

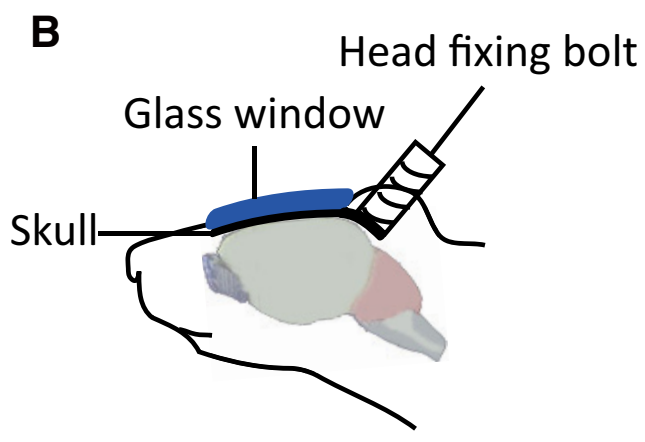

Transcranial window

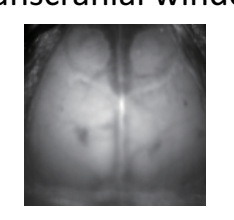

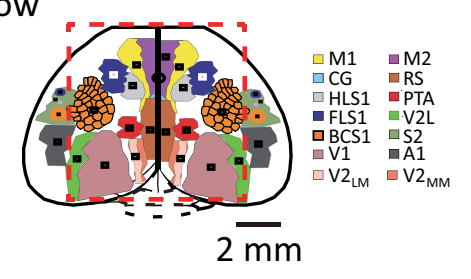

Figure 1. Setup and surgical preparation for wide-field imaging with genetically encoded sensors. $A, A C C D$ camera was used to image cortical iGluSnFR signals $(\lambda=530 \mathrm{~nm})$ excited by blue $L E D$ $(\lambda=473 \mathrm{~nm}) \cdot \boldsymbol{B}$, A chronic window was implanted on the top of mouse skull after removing skin. The chronic window is relatively transparent, covering $\sim 8 \mathrm{~mm} \times 8 \mathrm{~mm}$ field of view on the cortex, including the motor, somatosensory, visual, and association cortices. M1, Primary motor; $\mathrm{CG}$, anterior segment of cingulate cortex; HLS1, hindlimb area of the primary somatosensory cortex; FLS1, forelimb area of the primary somatosensory cortex; $\mathrm{BCS1}$ : primary barrel sensory cortex; $\mathrm{V} 1$, primary visual cortex; $\mathrm{V}_{\mathrm{LM}}$, lateromedial visual cortex; $\mathrm{M} 2$, secondary motor cortex; $\mathrm{RS}$, retrosplenial cortex; PTA, parietal association area; V2L, lateral secondary visual cortex; $\mathrm{S2}$, secondary somatosensory cortex; A1, auditory cortex; V2 ${ }_{\mathrm{MM}}$ : mediomedial secondary visual cortex.

lar potentials using electrodes. However, microelectrode-based methods are limited due to the small number of cells that can be simultaneously recorded. Voltage-sensitive dyes (VSDs) provide cellular and regional measures of neuronal excitation and inhibition (Grinvald and Hildesheim, 2004; Ferezou et al., 2007; Akemann et al., 2010), but are not direct measures of synaptic activity. Calcium indicators provide exquisite sensitivity due to relatively large changes of indicator fluorescence associated with physiological $\mathrm{Ca}^{2+}$ transients (Grynkiewicz et al., 1985; Tian et al., 2009). Although calcium indicator signals can be large, they can nonlinearly relate to calcium concentration (Rose et al., 2014), which in turn has a complex relationship to membrane voltage (Berger et al., 2007). Furthermore, the signals of genetically encoded calcium-indicators (GECIs) have relatively slow kinetics, limiting their use in multicell-imaging applications to detection of spike-related signals at low frequencies. In addition, $\mathrm{Ca}^{2+}$ imaging is most appropriate for monitoring suprathreshold events (Chen et al., 2013b). Despite the limiting kinetics of calcium modalities, the current generation of intracellular calcium sensors are more than sufficient for mapping neuronal activity with low time resolution on the order of seconds (Tian et al., 2009; Chen et al., 2013b; Vanni and Murphy, 2014), but may not directly follow higher-frequency circuit dynamics.

Recently, organic dyes or genetically encoded sensors for neurotransmitters, including the major excitatory neurotransmitter glutamate, have been developed (Hires et al., 2008; Okubo et al., 2010; Marvin et al., 2013). Here, we use a genetically encoded glutamate sensor, iGluSnFR (Marvin et al., 2013), in vivo to assess cortical activity and intracortical functional connectivity. iGluSnFR is targeted to neurons and detects extracellular glutamate concentration with $\sim 1 \mathrm{~ms}$ rise and $40 \mathrm{~ms}$ decay times when tested using glutamate uncaging in vitro (Marvin et al., 2013). This rise time is much faster than the $\sim 10 \mathrm{~ms}$ time scale of sensory response rise time measured in vivo using organic VSDs (Ferezou et al., 2007; Sachidhanandam et al., 2013), indicating that iGluSnFR assessment of sensory processing is not limited by slow kinetics.
A functional marker of glutamate concentration amenable to mesoscopic imaging has several advantages, including detection of an endogenous neurotransmitter with clear functional significance. Indeed, the utility of a glutamate reporter for the characterization of normal and pathologic brain states is obvious due to glutamate's role in synaptic transmission, plasticity, and learning, as well as in illnesses such as stroke or in psychopathology. We report the in vivo characterization of iGluSnFR using both AAVinjected and transgenic mice. Specifically, in both anesthetized and awake states, we used both spontaneous and sensory-evoked activity to characterize the sensitivity, specificity, and kinetics of this new rapid sensor compared with existing sensors.

\section{Materials and Methods}

Procedures. All procedures were approved by the University of British Columbia Animal Care Committee and conformed to the Canadian Council on Animal Care and Use guidelines. Mice were housed in clear plastic cages in groups of two to five under a $12 \mathrm{~h}$ light, $12 \mathrm{~h}$ dark cycle with ad libitum food and water.

Animals. Adult (2-4 month) C57BL/6J mice from Charles River Laboratories were acquired for viral injection experiments and VSD imaging experiments using wide-field epifluorescence imaging (Fig. 1). Transgenic mice were imaged at adulthood (2-4 month). In all experiments, only male mice were used.

We generated Emx-CaMKII-iGluSnFR transgenic mice by crossing the homozygous B6.129S2-Emx1 $1^{\mathrm{tm} 1(\mathrm{cre}) \mathrm{Krj}} / \mathrm{J}$ strain (Jax no. 005628) and the B6.Cg-Tg(CamK2a-tTA)1Mmay/DboJ strain (Jax no.007004) with the hemizygous B6;129S-Igs7 ${ }^{\text {tm } 85 \text { (teto-iGluSnFR)Hze/J strain (the Allen }}$ Institute for Brain Science, Ai85). This crossing is expected to produce expression of iGluSnFR within all excitatory neurons across all layers of the cortex, but not in GABAergic neurons (Gorski et al., 2002; Huang and Zeng, 2013; Madisen et al., 2015).

We generated Emx-CaMKII-GCaMP6s transgenic mice by crossing

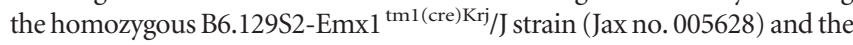
B6.Cg-Tg(CamK2a-tTA)1Mmay/DboJ strain (Jax no.007004) with the

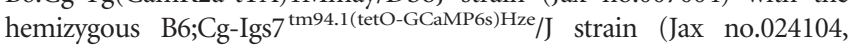
Ai94) (Madisen et al., 2015). As described previously (Zariwala et al., 2012; Vanni and Murphy, 2014), we generated Emx-GCaMP3 mice by crossing the homozygous B6.129S2-Emx1 ${ }^{\mathrm{tml} \text { (cre)Krj } / J ~ s t r a i n ~(J a x ~ n o . ~ 005628) ~ w i t h ~ t h e ~}$ 
Table 1. A list of genotyping information for transgenic mice in the study

\begin{tabular}{|c|c|c|c|c|}
\hline & Forward & Reverse & $\begin{array}{l}\text { Product } \\
\text { size (bp) }\end{array}$ & Jax no. \\
\hline aMKII-tTA & $\begin{array}{l}\text { CAACCCGTAAACTCGCC } \\
\text { CAGAAG }\end{array}$ & $\begin{array}{l}\text { GGCCGAATAAGAAGGCT } \\
\text { GGCTCT }\end{array}$ & 492 & 007004 \\
\hline Emx-Cre & $\begin{array}{l}\text { GCGGTCTGGCAGTAAAAA } \\
\text { CTATC }\end{array}$ & $\begin{array}{l}\text { GTGAAACAGCATTGCTG } \\
\text { TCACTT }\end{array}$ & 330 & 005628 \\
\hline GCaMP6s (Ai94) & $\begin{array}{l}\text { CAGCTCGCCTACCACTAC } \\
\text { CAGCA }\end{array}$ & $\begin{array}{l}\text { TTGAAGAAGATGGTGCGC } \\
\text { TCCTG }\end{array}$ & 509 & 024104 \\
\hline iGluSnFR (Ai85) & $\begin{array}{l}\text { ACTCCAACGCCATTGTT } \\
\text { GAAGCA }\end{array}$ & $\begin{array}{l}\text { GTTTCTTCGCTTTCGCA } \\
\text { CGTTCA }\end{array}$ & 450 & In process \\
\hline GCaMP3 (Ai38) & $\begin{array}{l}\text { CTTCAAGATCCGCCACA } \\
\text { ACATCG }\end{array}$ & $\begin{array}{l}\text { TTGAAGAAGATGGTGGG } \\
\text { СTCCTG }\end{array}$ & 546 & 014538 \\
\hline
\end{tabular}

hemizygous B6;129S-Gt(ROSA) 26Sortm38(CAG-GCaMP3)Hze/J strain (Jax no. 014538, Ai38). Animals with the desired combination of transgenes were selected on the basis of genotyping data (Table 1).

Viral injection. Viral delivery of iGluSnFR involved $1 \mu \mathrm{l}$ of AAV1.hSyn.iGluSnFR.WPRE.SV40 (Penn Vector Core) injected by a syringe infusion pump (model UMC4; World Precision Instruments) as described previously (Xie et al., 2014). C57BL/6J mice were injected (depth: $\sim 350 \mu \mathrm{m}$; infusion speed: $\sim 1 \mathrm{nl} / \mathrm{s}$ ) 3-4 weeks before implantation of the cranial window and imaging. Injections were performed at 3 sites: (1) motor cortex (1 mm anterior and $2 \mathrm{~mm}$ lateral to bregma); (2) somatosensory cortex ( $1.5 \mathrm{~mm}$ posterior and $2.5 \mathrm{~mm}$ lateral to bregma); and (3) visual cortex ( $3.5 \mathrm{~mm}$ posterior and $2 \mathrm{~mm}$ lateral to bregma) (Fig. $2 A)$. Isoflurane $(1.5 \%)$ in oxygen was used for anesthesia.

Surgical procedures for implanting chronic transcranial window. To implant chronic windows (Fig. $1 B$ ), animals were anesthetized with isoflurane $\left(1.5 \%\right.$ in $\left.\mathrm{O}_{2}\right)$ and body temperature was maintained at $37^{\circ} \mathrm{C}$ using a feedback-regulated heating pad and monitored by a rectal thermometer. Mice received an intramuscular injection of $40 \mu \mathrm{l}$ of dexamethasone (2 $\mathrm{mg} / \mathrm{ml}$ ) and a $0.5 \mathrm{ml}$ subcutaneous injection of a saline solution containing buprenorphine $(2 \mu \mathrm{g} / \mathrm{ml})$, atropine ( $3 \mu \mathrm{g} / \mathrm{ml})$, and glucose (20 mM) and were placed in a stereotaxic frame. After locally anesthetizing the scalp with lidocaine $(0.1 \mathrm{ml}, 0.2 \%)$, the skin covering the skull was removed and replaced by transparent dental cement (Parkell C\&B Metabond) and a glass coverslip (Fig. 1B; Silasi et al., 2013; Vanni and Murphy, 2014). A 4-40 metal stud was attached to the skull for future head fixation during recordings. At the end of the procedure, the animal received a second subcutaneous injection of saline $(0.5 \mathrm{ml})$ with $20 \mathrm{~mm}$ glucose and recovered in a warmed cage for $30 \mathrm{~min}$. For subsequent chronic recordings, animals were anesthetized with isoflurane $(\sim 1.5 \%)$ to produce a constant level of cortical activity and the head was stabilized by attaching the bolt to a pole mounted on a base plate. Body temperature was maintained at $\sim 37^{\circ} \mathrm{C}$ and hydration was supported by subcutaneous injection of saline $(0.3 \mathrm{ml})$ with $20 \mathrm{~mm}$ glucose at $2 \mathrm{~h}$ intervals. In most cases, longitudinal imaging with the chronic window could last $>2$ months (Fig. 3E).

Craniotomy and VSD imaging. VSD imaging was performed in acute experiments as we described previously (Mohajerani et al., 2010, 2013) using RH 1692 dye (Optical Imaging; Shoham et al., 1999). Ten-weekold mice were anesthetized with isoflurane $(1.5 \%)$ for induction and during craniotomy surgery. Mice were placed on a metal plate that could be mounted onto the stage of the upright macroscope and the skull was fastened to a steel plate. A $7 \times 6 \mathrm{~mm}$ unilateral craniotomy (bregma 2.5 to $-4.5 \mathrm{~mm}$, lateral $0-6 \mathrm{~mm}$ ) or bilateral craniotomy (bregma 2.5 to $-4.5 \mathrm{~mm}$, lateral $0-3 \mathrm{~mm}$ in both sides) was made and the underlying dura was removed. Throughout surgery and imaging, body temperature was maintained at $37^{\circ} \mathrm{C}$ using a heating pad with a thermistor for feedback. RH-1692 voltage sensitive dye was dissolved in HEPES-buffered saline solution $(1 \mathrm{mg} / \mathrm{ml})$ and applied to the exposed cortex for $90 \mathrm{~min}$, which stained all neocortical layers. The brain was covered with $1.5 \%$ agarose made in HEPES-buffered saline and sealed with a glass coverslip. VSD was excited with light delivered by a red LED (Luxeon K2, $627 \mathrm{~nm}$ center) through a $630 \pm 15 \mathrm{~nm}$ excitation filter. Ambient light resulting from VSD excitation $(630 \mathrm{~nm})$ was $\sim 1-2 \mathrm{~mW}$ over the $8 \times 8 \mathrm{~mm}$ area used for imaging. Imaging was performed under light anesthesia (isoflurane, $0.75 \sim 1 \%)$. VSD epifluorescence was imaged through a $688 \pm 15$ $\mathrm{nm}$ band-pass filter (Semrock).

Sensory stimulation and imaging. Images of the cortical surface were projected through a pair of back-to-back photographic lenses $(50 \mathrm{~mm}$, $1.4 \mathrm{f}: 135 \mathrm{~mm}, 2.8$ f or $50 \mathrm{~mm}, 1.4 \mathrm{f:30} \mathrm{mm,2} \mathrm{f}$ ) onto a $1 \mathrm{M} 60$ Pantera CCD camera (Dalsa). iGluSnFR and GCaMP were excited with light from a blue-light-emitting diode (Luxeon, $473 \mathrm{~nm}$ ) delivered through a band-pass filter (Chroma, 467-499 nm). Ambient light resulting from iGluSnFR and GCaMPs excitation $(473 \mathrm{~nm})$ was $\sim 1-2 \mathrm{~mW}$ over the $8 \times$ $8 \mathrm{~mm}$ area used for imaging. iGluSnFR and GCaMP fluorescence emission was filtered using a $510-550 \mathrm{~nm}$ band-pass filter (Chroma). We collected 12-bit images at $150 \mathrm{~Hz}$ using XCAP imaging software (Fig. $1 A$ ). When collecting somatosensory-evoked cortical activity, we used piezoelectric bending actuators touching the skin of single limb or individual or multiple whiskers, which moved at most $90 \mu \mathrm{m}$ in an anteriorto-posterior direction (a $2.6^{\circ}$ angle of deflection). Visual stimulation was produced by a $1 \mathrm{~ms}$ pulse of light from a $435 \mathrm{~nm}$ LED placed at a consistent height and distance from the right eye. Averages of responses to sensory stimulation were calculated from 20 trials of stimulation with an interstimulus interval of $10 \mathrm{~s}$. Awake mice were placed on a flat running wheel with the head stabilized by attaching the fixation bolt to a pole mounted on a base plate (Fig. $2 \mathrm{Fa}$ ) and were habituated for two to three sessions before imaging. A camera $(30 \mathrm{~Hz})$ was used to monitor behavior, confirming that the animals were awake and showed no signs of distress.

Analysis for wide-field imaging. All green fluorescent protein (GFP) indicators have excitation spectra that overlap with the absorption spectrum of hemoglobin (Hillman, 2007), whereas red-shifted VSD signals are not significantly contaminated by heartbeat pulses and hemodynamic responses (Shoham et al., 1999; Petersen et al., 2003; Chan et al., 2015). To remove the contribution of global hemodynamic and potential illumination fluctuations from iGluSnFR and GCaMP imaging, raw data were corrected with signal regression (Aguirre et al., 1998; Fox et al., 2009) for each pixel with the following:

$$
S_{i}(t)=g(t) * A_{i}+x_{i}(t)
$$

where $g(t)$ is a regressor, $A_{i}$ is the regression coefficient, and $x_{i}$ is the signal within the $i$ th pixel after regression. Here, global signal regression (GSR) was used. Time traces of all pixels defined as brain were averaged to create a global brain signal, $g_{\mathrm{GSR}}(t)$, and regressed from every pixel labeled as brain, as follows:

$$
g_{G S R}(t)=\frac{1}{N} \sum_{j=1}^{N} S_{j}(t)
$$

where $N$ is the number of all brain pixels in the field of view $(128 \times 128$ pixels, $66.7 \mu \mathrm{m}$ per pixel).

To calculate the iGluSnFR and GCaMP responses evoked by sensory stimulation, images collected from the 20 trials were averaged and the normalized difference to the average baseline $(\sim 50 \mathrm{~ms})$ before stimulation was calculated $\left(\Delta F / F_{0}\right.$; region of interest $(\mathrm{ROI})=667 \mu \mathrm{m} \times 667$ $\mu \mathrm{m})$. GSR was applied for each trial to remove global fluctuations produced by blood volume changes and hemodynamic responses.

The peak of sensory-evoked responses was defined as the largest $\Delta F / F_{0}$ value averaged from a $10 \times 10$ pixels ROI placed within V1 within $200 \mathrm{~ms}$ (iGluSnFR and VSD) or $1000 \mathrm{~ms}$ (GCaMP3 and GCaMP6s) after sensory stimulation. Peak amplitude measurements that were $<3$ times the SD of baseline fluctuations ( $\sim 50 \mathrm{~ms}$ ) were classified as a failed response (peak $\left.\Delta F / F_{0}=0\right)$ and were excluded from time to peak and decay $\tau_{1 / 2}$ analysis. The decay $\tau_{1 / 2}$ was calculated as the time to half the peak amplitude. Signal-to-noise ratio (SNR) was quantified as peak $\Delta F / F_{0}$ response over the SD during baseline and calculated on averaged responses (20 sweeps per animal).

Spontaneous activity of each ROI in the recording sequence was calculated by dividing each frame by the mean fluorescence of the entire time series $\left(F_{0}\right)$. The result of iGluSnFR, GCaMP, and VSD signals was then temporally band-pass filtered to the indicated frequency bands using the Chebyshev in MATLAB (R2014b; The MathWorks) and then GSR was applied. To create the seed pixel correlation map, cross- 
A

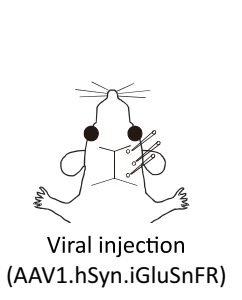

B

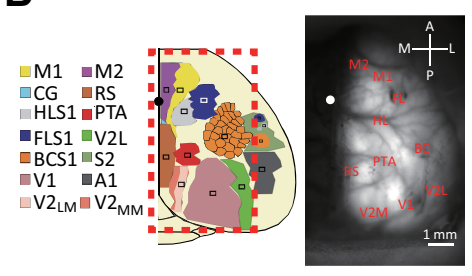

C

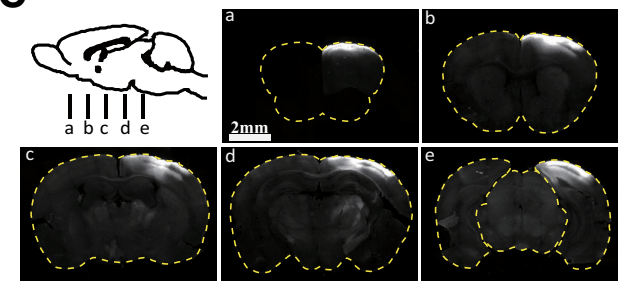

D

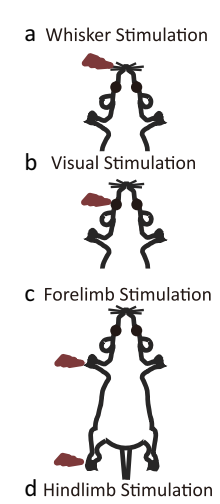

Anesthetized - $1.5 \%$ isoflurane

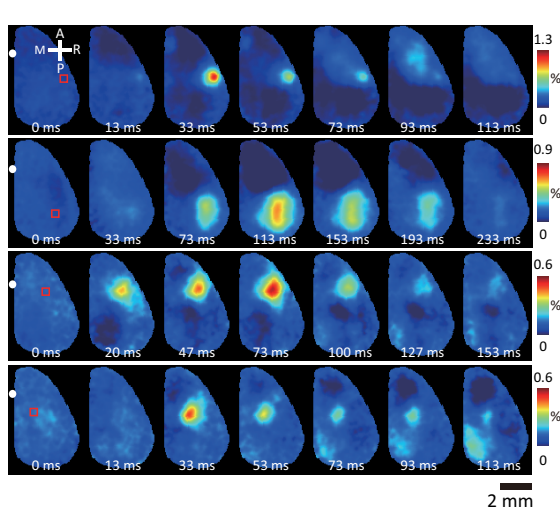

E

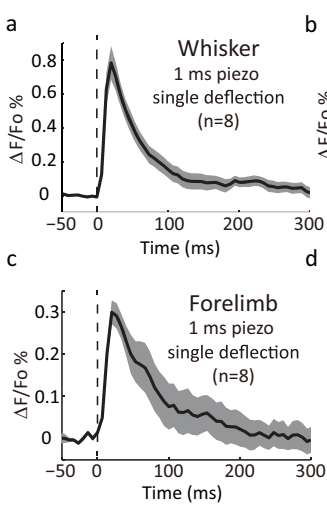

b

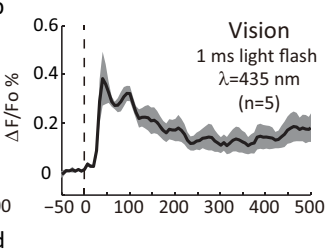

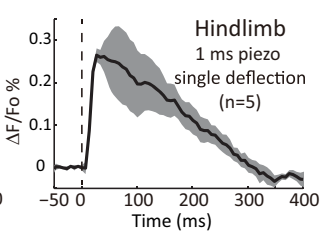

$\mathbf{F}_{\text {a }}$

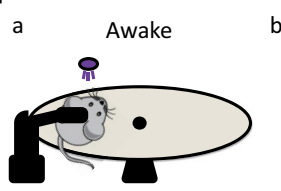

b 1 ms light flash: $\lambda=435 \mathrm{~nm}$
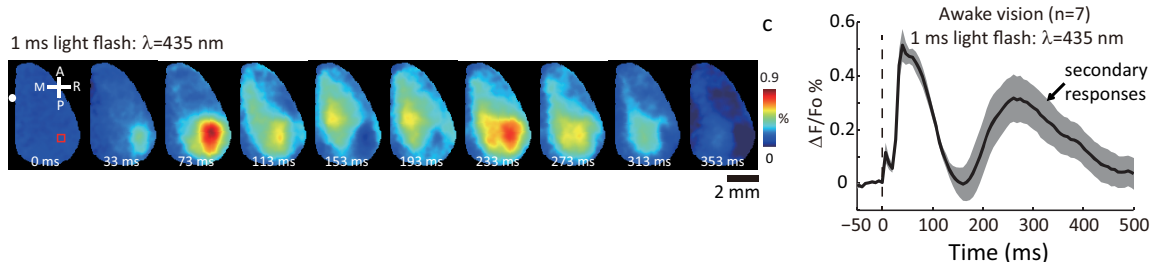

Figure 2. Virally transduced iGluSnFR robustly reports sensory-evoked responses in the cortex. A, AAV1.hSyn.GGluSnFR was injected into the forelimb, barrel, and visual cortex $\sim 4$ weeks before implanting the chronic window. $B$, Expression of virally transduced iGluSnFR in half of the hemisphere across the motor, somatosensory, and visual cortex. C, Brain slice sections show that the virally transduced iGluSnFR is expressed in the superficial layers of the cortex. $\boldsymbol{D}$, Multiple sensory-evoked cortical responses in virally transduced iGluSnFR mouse show sensitive, specific, and rapid event-related kinetics at under 1.5\% isoflurane anesthesia. Representative montage shows the iGluSnFR responses in the cortex after sensory stimulation and is averaged from 20 trials. $E$, Time course plots of sensory-evoked responses ( $E \boldsymbol{G}-\boldsymbol{E d}$ are whisker, visual, forelimb, and hindlimb stimulation, respectively; mean $\pm \mathrm{SEM}$ ) measured from the respective primary sensory region [region of interest (ROI): $667 \times 667 \mu \mathrm{m}, n=$ number of animals]. $F$, A 1 ms flash light visual stimulation induces an initial rapid response, followed by a clearly separated, delayed secondary response in the awake mouse. $F \boldsymbol{a}$, Scheme illustrating the experimental setup of visual stimulation in the awake mouse. $\boldsymbol{F b}$, Representative montage of cortical iGluSnFR responses after visual stimulation (mean of 20 trials). Fc, Plot of light flash-evoked visual responses shown as mean \pm SEM from $667 \times 667 \mu \mathrm{m}$ boxes placed within V1 (red box shown in $\boldsymbol{F b})(n=$ number of animals).

correlation coefficient $r$ values between the temporal profiles of a single selected pixel and all the other pixels of the ROI were calculated (White et al., 2011; Mohajerani et al., 2013). For every map presented, spatial smoothing $(\sigma=67-134 \mu \mathrm{m})$ was applied to improve contrast. Ongoing brain activity during active whisking or other significant movements (recorded by behavior camera) were excluded from spontaneous activity in awake animals. The total duration of spontaneous activity was maintained constant for all animals $(20,000$ frames recorded at $150 \mathrm{~Hz})$ when generating correlation maps.

Two-photon imaging and data analysis. Two-photon (2P) imaging was performed as described previously (Xie et al., 2012, 2014). Briefly, a small craniotomy $(3 \times 3 \mathrm{~mm})$ was made over the visual cortex. $2 \mathrm{P}$ excitation was performed with a Mai Tai Ti-sapphire laser and tuned to $920 \mathrm{~nm}$ to excite iGluSnFR (Marvin et al., 2013). All experiments were performed using a $20 \times$ objective (Olympus, numerical aperture $=0.95$ ) immersed in HEPES-buffered saline solution. Time series images were acquired at frame rates of $\sim 20 \mathrm{~Hz}$ and at $100-150 \mu \mathrm{m}$ depth from the surface of cortex. A median filter (radius, 1 pixel) was applied to reduce photon and photomultiplier tube noise. $\Delta F / F_{0}$ value was calculated to describe the responses upon $1 \mathrm{~ms}$ light flash stimulation. The stimulus light source was isolated from the detectors and we did not detect imaging artifacts from light stimulation. Spontaneous activity was processed the same way that it was for the wide-field imaging.
Pharmacology. A small craniotomy $(3 \times 3 \mathrm{~mm})$ was made over the visual cortex $(n=4)$. Threo-beta-benzyloxyaspartate (TBOA; Tocris Bioscience), a glutamate transporter blocker, was dissolved into DMSO to $50 \mathrm{~mm}$ as stock solution and then diluted with HEPES-buffered saline solution to $500 \mu \mathrm{M}$ for direct cortical incubation. The compound was allowed to incubate for $>20$ min before starting imaging of spontaneous and visual stimulation-evoked activity.

Transcardial perfusion and brain slice imaging. Mice were transcardially perfused with PBS, followed by chilled $4 \%$ paraformaldehyde in PBS. Coronal brain sections (100 $\mu \mathrm{m}$ thickness) were cut on a vibratome (Leica VT1000S). Images were acquired with a Zeiss Axiovert 200M fluorescence microscope using ZEN 2012 software.

\section{Results}

Cortical mapping of sensory-evoked responses by virally transduced iGluSnFR through a chronic window

We first used viral expression of iGluSnFR to characterize the in vivo kinetics of the iGluSnFR sensor using cortical responses to sensory stimulation. AAV1.hSyn.iGluSnFR was injected into the motor cortex, somatosensory cortex, and visual cortex (Fig. 2A) to exclusively express iGluSnFR in cortical neurons (Aschauer et al., 2013). The probe is expected to measure extracellular gluta- 
A

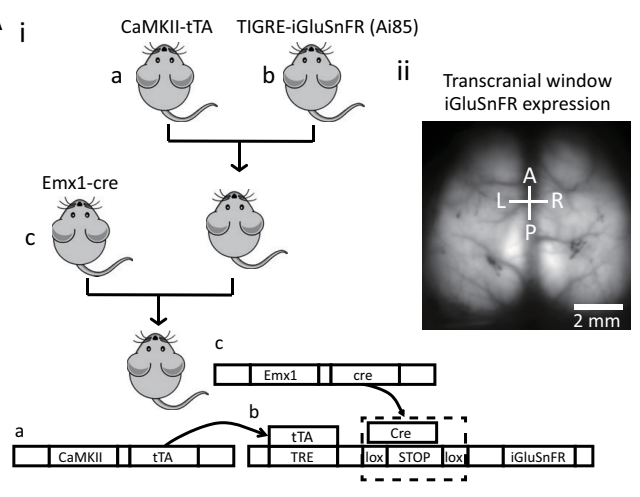

C

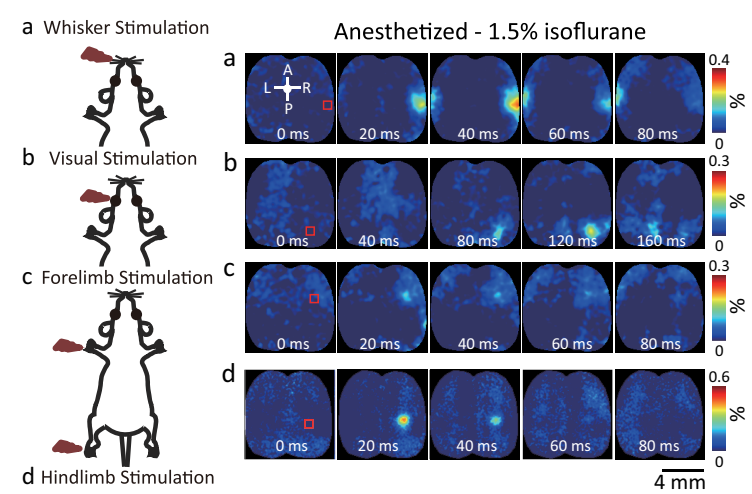

B

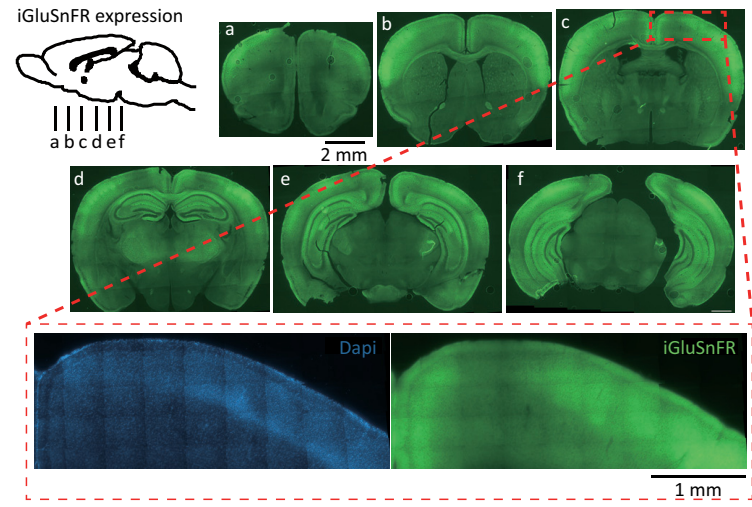

D
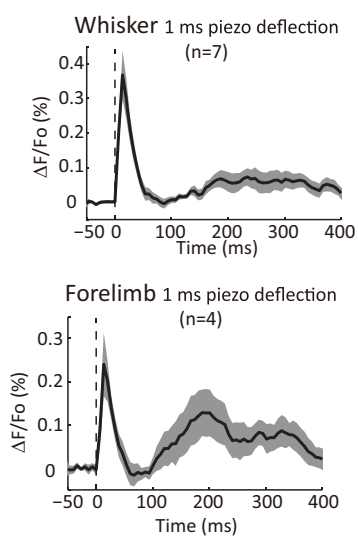

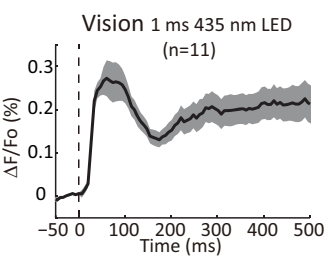

Hindlimb $1 \mathrm{~ms}$ piezo deflection

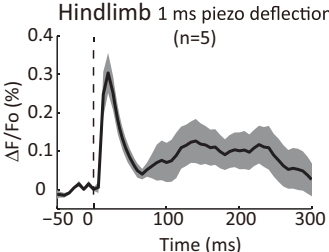

E
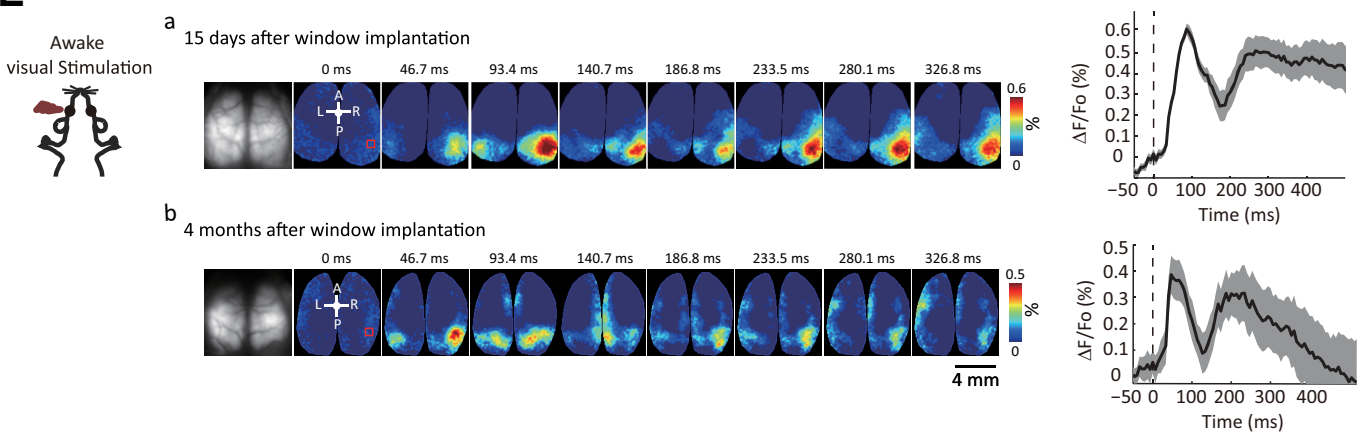

Figure 3. Ai85 transgenic iGluSnFR mouse reveals the sensitive, specific, and rapid kinetics of iGluSnFR by detecting sensory stimulation-evoked regional responses in the cortex. Ai, Specific expression of iGluSnFR in cortical excitatory neurons is achieved by crossing Emx-Cre mouse line and Cre-dependent iGluSnFR to the CaMKIl gene locus, Aii, Emx-CaMKII-iGluSnFR mouse exhibits uniform cortical expression of iGluSnFR at the mesoscopic level. Image shows the wide-field green fluorescence from the cortex. B, Coronal brain sections show dense expression of iGluSnFR in cortex and hippocampus in Emx-CaMKII-iGluSnFR mouse. Coronal sections (Ba-Bf) correspond to locations indicated in schematic diagram. $\boldsymbol{C}$, Brief sensory stimulation evokes large and fast cortical responses of iGluSnFR signals in Emx-CaMKII-iGluSnFR mouse. Representative montage of 20 trials averaged iGluSnFR responses after sensory stimulation. D, Plots of sensory-evoked responses are mean \pm SEM from $667 \times 667 \mu \mathrm{m}$ boxes placed within the corresponding primary sensory cortices denoted by the red boxes in $C(n=$ number of animals). $E$, A 1 ms flash light visual stimulation induces an initial fast response followed by a clearly separated secondary response in awake Emx-CaMKII-iGluSnFR mouse. Ea, $\boldsymbol{E} b$, Representative montage of iGluSnFR responses after visual stimulation in the same animal 4 months apart. Representative montage of 20 trials averaged iGluSnFR responses after visual stimulation. Plot of visual responses shown as mean \pm SEM from $667 \times$ $667 \mu \mathrm{m}$ boxes placed within V1 (red boxes in $E \boldsymbol{a}$ and $E \boldsymbol{b}, n=20$ trials).

mate in the vicinity of infected neurons, but is not targeted to a particular subcellular compartment. Three weeks after AAV injection, we observed a wide spatial expression of iGluSnFR covering almost the entire cortical hemisphere visible within the chronic window, including the somatosensory, motor, visual, and some of the association cortices (Fig. 2B). As expected, there was higher expression near the injection sites (layer 1-3, Fig. 2C). The distribution of viral iGluSnFR expression in deep layers (layer 4-6) was not as uniform as in superficial layers (Fig. 2C).
We imaged different modalities of sensory-stimulationevoked glutamate signals under $1.5 \%$ isoflurane anesthesia. We found that iGluSnFR was sensitive enough to detect responses to relatively weak stimuli, a single $1 \mathrm{~ms}$ piezo deflection of the whisker pad or tap to the plantar surface of forelimb or hindlimb (Fig. 2D,E), which was insufficient to elicit GCaMP3 signals (data not shown). We also imaged cortical glutamate levels after visual stimulation (1 ms light flash) in anesthetized and awake animals. Under both conditions, iGluSnFR signals can be clearly observed in the visual cortex 
(Fig. 2D,F). Interestingly, $1 \mathrm{~ms}$ visual stimulation induced consistent secondary responses at $\sim 200-400 \mathrm{~ms}$ in awake animals, which was not clearly observed in $1.5 \%$ isofluraneanesthetized animals (Fig. $2 E b, F c$ ).

\section{Regional mapping of sensory stimulation-evoked responses by transgenic iGluSnFR through a chronic window}

To achieve a more uniform expression of iGluSnFR and to reduce methodological limitations related to viral injection (e.g., traumatic injury, inflammation, etc.), we acquired transgenic mice (Ai85) from the Allen Institute for Brain Science (Madisen et al., 2015). The expression, kinetics, and in vivo function of these genetically encoded iGluSnFR animals was not previously functionally characterized. Using a tTA-based transcriptional amplification approach targeted to the TIGRE insertion locus, iGluSnFR was intersectionally and doubly regulated by both Cre and tTA to drive robust expression with improved precision to a targeted cell population (Huang and Zeng, 2013; Madisen et al., 2015). Crossing Emx1-Cre with CaMKII-tTA and TIGREiGluSnFR (Fig. 3Ai) resulted in robust and uniformly expressed iGluSnFR within the chronic cortical window (Fig. 3Aii). Brain sections of the positive transgenic mice confirmed robust expression in the cortex and hippocampus (Fig. 3B) (Madisen et al., 2015). It was difficult to resolve subcellular expression of iGluSnFR in the cortex due to the dense expression of membrane protein (Fig. 3B; Marvin et al., 2013; Madisen et al., 2015). iGluSnFR expression using our approach is designed to be doubly regulated by Emx-Cre and CaMKII-tTA to express selectively in the excitatory neurons of the cortex (Mayford et al., 1996; Gorski et al., 2002) and is consistent with other recently developed lines using the same approach (Madisen et al., 2015).

We performed sensory mapping of the Emx-CaMKIIiGluSnFR mouse under $1.5 \%$ isoflurane anesthesia. Stimulation was performed as in the virally infected mice using stimuli produced by single piezo deflections on the whisker pad, forelimb, and hindlimb plantar surface, as well as a $1 \mathrm{~ms}$ light flash for visual stimulation. Consistent with imaging from virally transduced iGluSnFR, we were able to detect responses in the cortex with high temporal and spatial resolution to even weak sensory stimuli in transgenic mice expressing iGluSnFR (Fig. 3C,D). Again, visual stimulation evoked large iGluSnFR signals in the visual cortex (Fig. 3C,D) and awake animals exhibited a secondary delayed response at $\sim 200-400 \mathrm{~ms}$ (Fig. 3E). A similar secondary response has been shown in the barrel cortex with whisker stimulation (Sachidhanandam et al., 2013) and in the visual cortex with light flash stimulation in awake mice (Funayama et al., 2015), which are both associated with sensory perception. Moreover, as with virally delivered iGluSnFR, transgenically expressed iGluSnFR demonstrated stable sensory evoked responses over time, thereby permitting longitudinal imaging (Fig. 3Eb).

\section{Intracortical long-range connections are observed using seed pixel correlation maps generated from spontaneous activity in Emx-CaMKII-iGluSnFR mice}

Resting-state spontaneous activity provides samples of brain activity and requisite functional connectivity without requiring the testing subjects to engage in tasks and therefore has utility in physiological and pathological brain states (Zhang and Raichle, 2010; van den Heuvel and Hulshoff Pol, 2010). Cortical restingstate activity assessed by voltage signals (Mohajerani et al., 2013), $\mathrm{Ca}^{2+}$ signals (Vanni and Murphy, 2014) and intrinsic signals (White et al., 2011) have been recently applied to determine regional functional connectivity and also aberrant functional connectivity caused by brain diseases in rodents (Bero et al., 2012; Bauer et al., 2014). To our knowledge, this type of widefield characterization of spontaneous activity by glutamatergic signaling — presumably reflecting synaptic activity-has not been reported previously.

Imaging spontaneous iGluSnFR signals in the cortices of mice under $1.5 \%$ isoflurane revealed robust signals of spontaneous activity (Fig. 4Aa). Processing the signals with GSR significantly reduced the artifacts related to breathing as well as heartbeatinduced blood-volume-related signals (Fig. 4Ab). Activitydependent autofluorescence is not expected to make a large contribution to the measured fluorescence signals because of the higher absolute fluorescence associated with iGluSnFR (DíezGarcía et al., 2007; Vanni and Murphy, 2014). We tested whether the mirrored bilateral activity identified with voltage and $\mathrm{Ca}^{2+}$ imaging (Mohajerani et al., 2010; Vanni and Murphy, 2014) was reflected in glutamatergic signals as detected by iGluSnFR. Figure $4 A a$ shows synchronized iGluSnFR signals in the left and right hindlimb somatosensory cortex (red and blue trace), which were not synchronized with iGluSnFR signals in the (left/right) visual cortex (green trace, Fig. 4Aa). Correlation maps of iGluSnFR signals in various frequency bands further confirmed the interhemisphere functional connectivity, as well as local connectivity (Fig. $4 B$ ). Placing the seed pixel in the center of sensory cortices, we generated maps using iGluSnFR (Fig. 4C) that resembled those with VSD signals and $\mathrm{Ca}^{2+}$ signals (Mohajerani et al., 2013; Vanni and Murphy, 2014), which are thought to be reflective of anatomical long-range connections within the cortex, but could also be attributed to regions sharing a common drive (Mohajerani et al., 2013; Hunnicutt et al., 2014; Oh et al., 2014; Zingg et al., 2014).

\section{Blocking glutamate transporter amplifies sensory stimulation evoked and spontaneous iGluSnFR signals}

Blocking excitatory amino acid transporter 1 and 2 (EAAT1 and EAAT2) with TBOA (Shimamoto et al., 1998) increases both the amplitude and the decay time constant of the spontaneous iGluSnFR events in the inner plexiform layer bipolar cells (Marvin et al., 2013). To confirm that wide-field iGluSnFR signals can also be manipulated by blocking glutamate reuptake in mouse cortex in vivo, $500 \mu \mathrm{M}$ TBOA was applied to the craniotomy over the visual cortex (Fig. 5A) and was allowed to incubate for $>20 \mathrm{~min}$ before imaging spontaneous and visual-stimulation-evoked activity. We previously demonstrated the cortical incubation enables drug diffusion into as deep as layer 5 (Xie et al., 2014). It should be mentioned that the open skull craniotomy (Fig. 5A) is relatively more invasive than the intact skull window (Fig. $1 B$ ). Blocking glutamate reuptake significantly increased the amplitude of iGluSnFR signals in response to $1 \mathrm{~ms}$ visual stimulation (first peak amplitude: baseline vs TBOA: $0.77 \pm 0.12 \%$ vs $1.17 \pm$ $0.22 \%, p<0.05$, mean \pm SEM, $n=4$, Fig. $5 B, C)$ and during spontaneous activity in the visual cortex (Fig. $5 D b$ ). In addition, the SD map during a period of $133 \mathrm{~s}$ spontaneous activity exhibited an $\sim 2$-fold increase within the craniotomy where TBOA had access to tissue (Fig. 5Da). These results demonstrate that blocking glutamate reuptake amplifies sensory stimulation-evoked and spontaneous iGluSnFR signals in wide-field imaging, which is consistent with results from cellular imaging in retina (Marvin et al., 2013). 
A

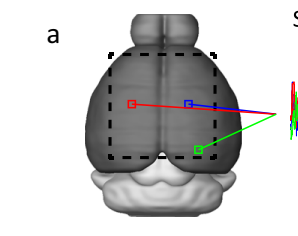

b

b PSD of signal in right hindlimb

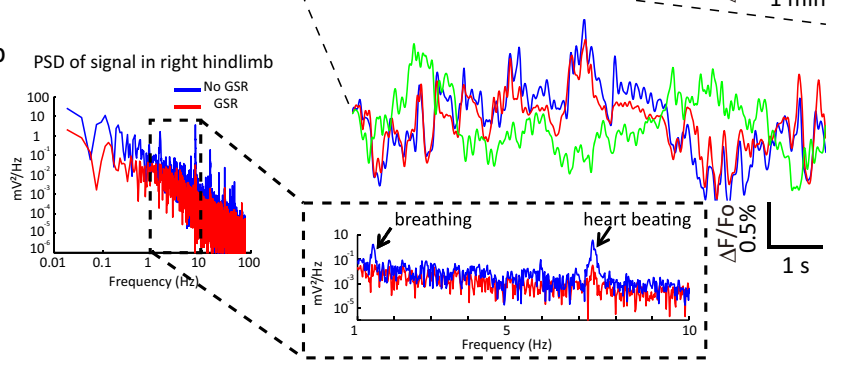

B

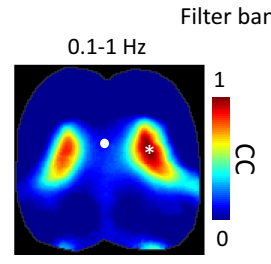

$12-30 \mathrm{~Hz}$

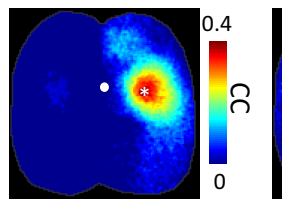

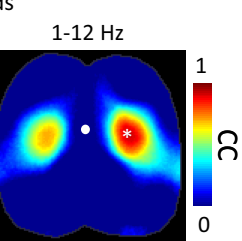

$30-70 \mathrm{~Hz}$

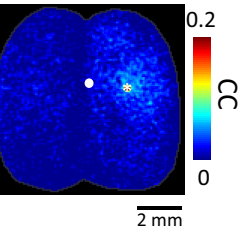

C

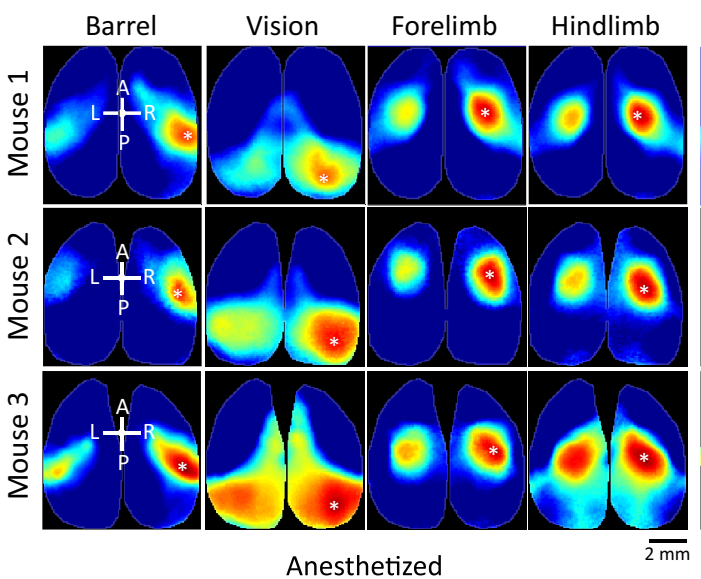

Barrel

Vision

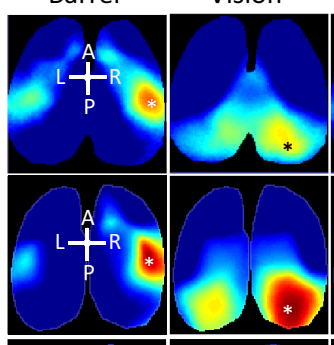

Forelimb

Hindlimb

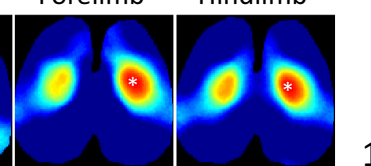

1

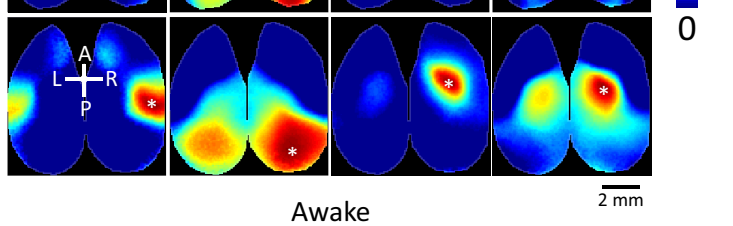

Figure 4. Interhemispheric connections are revealed by iGluSnFR spontaneous activity. Aa, Spontaneous iGluSnFR activity from $333 \times 333 \mu \mathrm{m}$ boxes placed in the left (red) and right hindlimb cortex (blue) as well as the right visual cortex (green) from an isoflurane-anesthetized (1.5\%) Emx-CaMKII-iGluSnFR (Ai85) mouse. Raw iGluSnFR imaging was recorded at $150 \mathrm{~Hz}$ and the signals were corrected with global signal regression (GSR) and band-pass filtered to $0.1-12 \mathrm{~Hz}$. Ab, Power spectral density (PSD) analysis indicates that iGluSnFR signals contain signal power likely contributed to by breathing and heartbeat-induced hemodynamic responses (arrows). GSR removes most of the heartbeat-related signals without significantly affecting the other signals. $\boldsymbol{B}$, Seed-pixel-based correlation maps of iGluSnFR signals show interhemispheric connections of left and right hindlimb cortex within $0.1-30 \mathrm{~Hz}$ frequency range in $1.5 \%$ isoflurane anesthetized Emx-CaMKII-iGluSnFR mouse. Asterisks indicate seed locations. C, Seed-pixel-based correlation maps of 0.1-12 Hz iGluSnFR activity illustrate the interhemisphere connections for different sensory modalities and also reveal long-range intrahemisphere connections (e.g., barrel cortex-motor cortex, visual cortex-cingulate cortex) in 3 animals $<1.5 \%$ isoflurane anesthesia and quiet wakefulness. Asterisks indicate seed locations. The maps are similar under anesthesia and quiet wakefulness in the same animal.

Two-photon in vivo imaging reveals the dense expression of iGluSnFR and confirms visual-stimulation-evoked responses in Emx-CaMKII-iGluSnFR mice

$2 \mathrm{P}$ in vivo imaging was applied to explore the cellular distribution of iGluSnFR expression and the cellular compartments where the spontaneous and evoked-activity occur in the visual cortex of Emx-CaMKII-iGluSnFR mice. Consistent with brain section histology (Fig. 3B), 2P imaging revealed a dense expression of iGluSnFR spanning a depth of at least $300 \mu \mathrm{m}$ in visual cortex (Fig. 6A). Consistent with wide-field imaging results, we observed a general increase in fluorescence intensity $\left(>1 \% \Delta F / F_{0}\right)$ from neuropil in superficial layers (imaged at a depth of 100-150 $\mu \mathrm{m}$ ) of visual cortex after a $1 \mathrm{~ms}$ light flash visual stimulation in $1 \%$ isoflurane-anesthetized Emx-CaMKII-iGluSnFR mice (Fig. 6B). In addition, 2P imaging also revealed spontaneous iGluSnFR signals (Fig. 6C). Despite challenges with respect to resolving the cellular origin of the iGluSnFR signals, 2P imaging resulted in improved signal, in part due to lessened blood volume artifacts, compared with wide-field.
iGluSnFR signal has faster kinetics for regional imaging of spontaneous and sensory-evoked responses than GCaMP3 and GCaMP6s

A key to obtaining real-time measures of ongoing neuronal activity and processing using imaging techniques is to employ the sensors with high sensitivity and fast kinetics. We next compared the response amplitude and kinetics of iGluSnFR signals with GCaMP3 signals and VSD signals. Although GCaMP3 signals have smaller amplitude than the fastest $\mathrm{Ca}^{2+}$ sensor, GCaMP6f (by $\Delta F / F_{0}$ under physiological conditions), they share a similar rise time ( $\tau_{\text {peak }}$ : GCaMP3 $137 \pm 4 \mathrm{~ms}$ vs GCaMP6f $80 \pm 35 \mathrm{~ms}, 10$ action potentials) and decay time $\left(\tau_{1 / 2}\right.$ : GCaMP3 $597 \pm 8 \mathrm{~ms}$ vs GCaMP6f $400 \pm 41 \mathrm{~ms}, 10$ action potentials) (Chen et al., 2013b). For comparison, 10 action-potential-associated iGluSnFR signals showed faster kinetics with $15 \pm 11 \mathrm{~ms}$ rise $\tau_{1 / 2}$ and $92 \pm 11 \mathrm{~ms}$ decay $\tau_{1 / 2}$ (Marvin et al., 2013).

We filtered the imaging data into delta $(0.1-4 \mathrm{~Hz})$, theta $(4-8$ $\mathrm{Hz}$ ), and alpha bands (8-12 Hz) (van Drongelen, 2007) to compare functional connectivity maps developed from seeds (Mohajerani et al., 2013) in the right hindlimb cortex. We applied the 
A

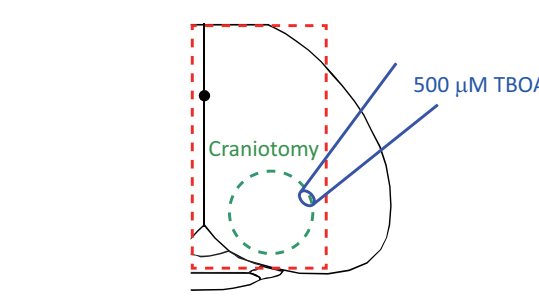

B

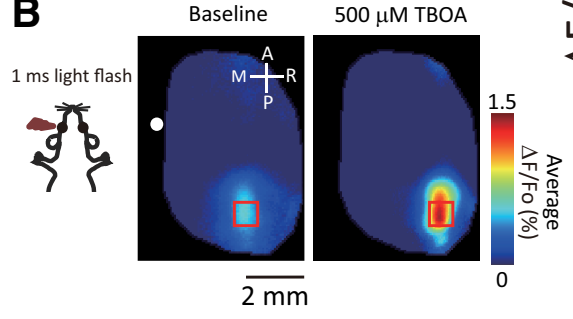

D

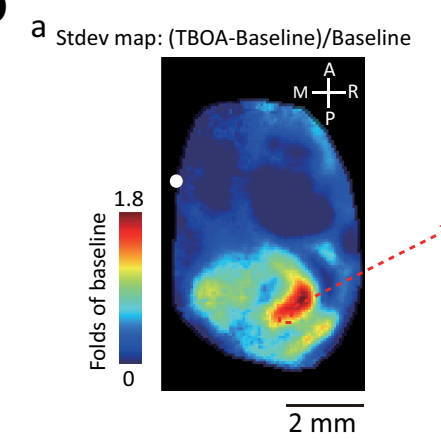

b

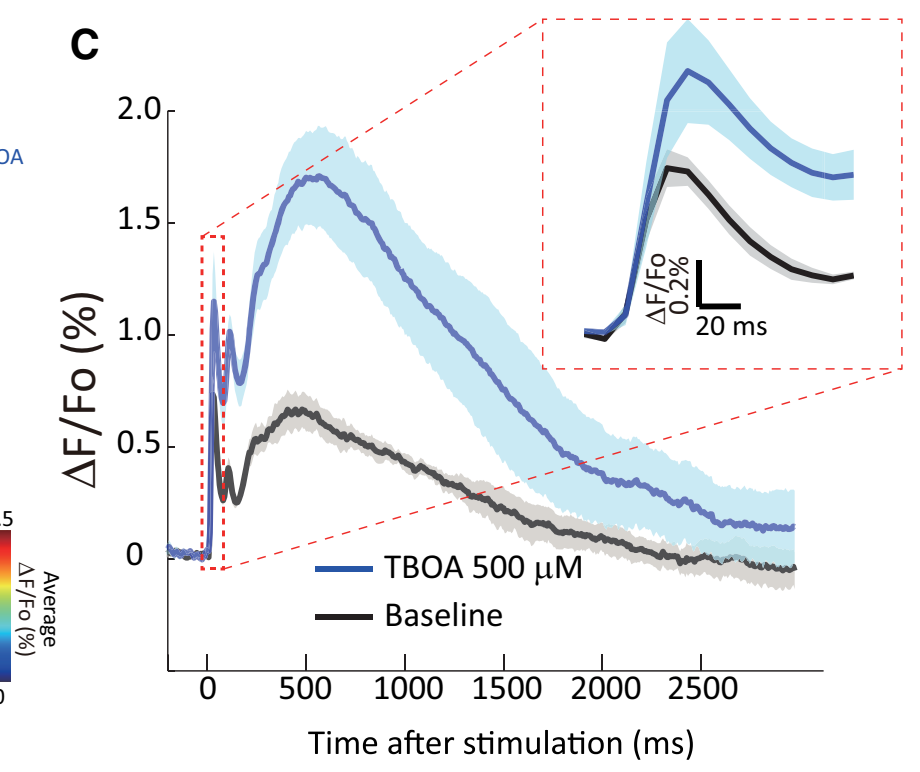

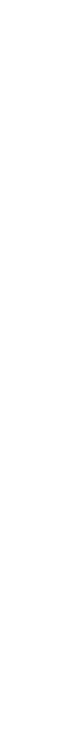


A

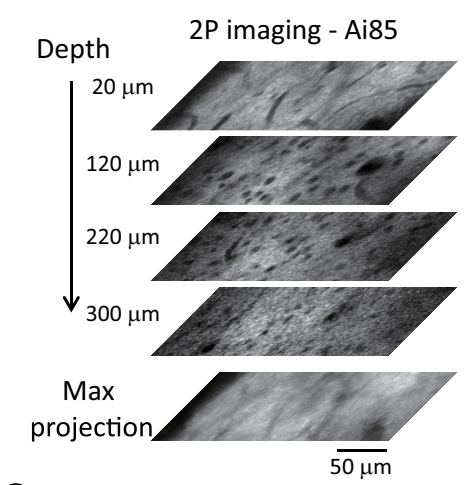

B

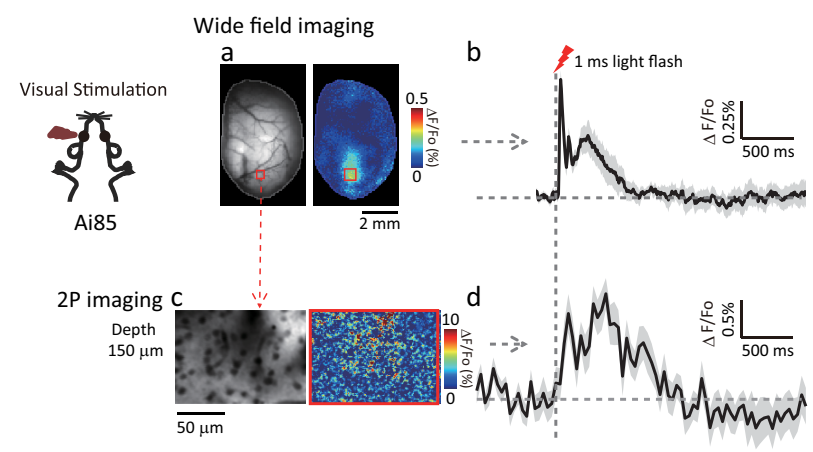

C

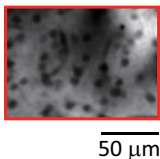

(1)

c

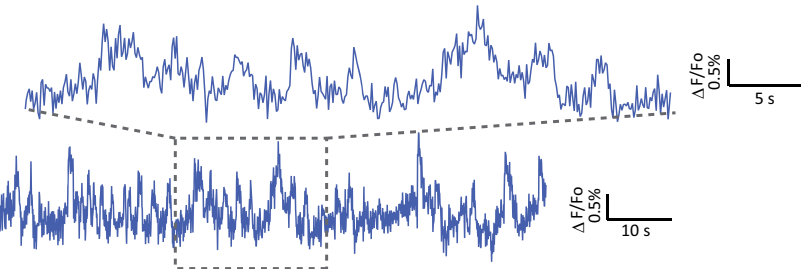

Figure 6. $2 \mathrm{P}$ imaging of sensory-evoked and spontaneous iGluSnFR signals in the visual cortex of Ai85 iGluSnFR transgenic mice. $A, 2 \mathrm{P}$ imaging reveals dense expression of iGluSnFR in the visual cortex of Emx-CaMKIl-iGluSnFR transgenic mice. Images show the depth series of iGluSnFR expression from brain surface to $-300 \mu \mathrm{m}$ depth and the maximal intensity projection of iGluSnFR expression from the first $300 \mu \mathrm{m}$ (3 $\mu \mathrm{m}$ interval for Z-scanning). B, A 1 ms light flash visual stimulation evokes a similar profile of iGluSnFR responses in the visual cortex of 1\% isofluraneanesthetized mouse in wide-field and two photon imaging. $\boldsymbol{B}$, Representative wide-field imaging shows iGluSnFR responses in the visual cortex (left, brain image; right, averaged map of iGluSnFR responses within the first second from the stimulation onset). $\boldsymbol{B} \boldsymbol{b}$, Plots of visual responses are shown as mean \pm SEM from $667 \times 667 \mu \mathrm{m}$ box placed within the V1 (red box in a-right; 20 trials). $B \boldsymbol{B}$, Representative 2P imaging shows iGluSnFR responses in the visual cortex (red box in $B \boldsymbol{a}$, left) at a depth of $-150 \mu \mathrm{m}$ (left, structural image; right, averaged map of iGluSnFR responses within the first second from stimulation onset). $\boldsymbol{B d}$, Plots of visual responses are shown as mean \pm SEM from the entire imaging field (red box in $\boldsymbol{B} \boldsymbol{c}$, right, 20 trials). $\boldsymbol{C}$, A representative trace of iGluSnFR spontaneous signals (blue) is shown. $\mathbf{C a}$, ROI for extracting spontaneous iGluSnFR signals. $\boldsymbol{C}$, Raw trace of iGluSnFR signals. (c, Higher magnification of iGluSnFR signals from the box in $\boldsymbol{C b}$.

A
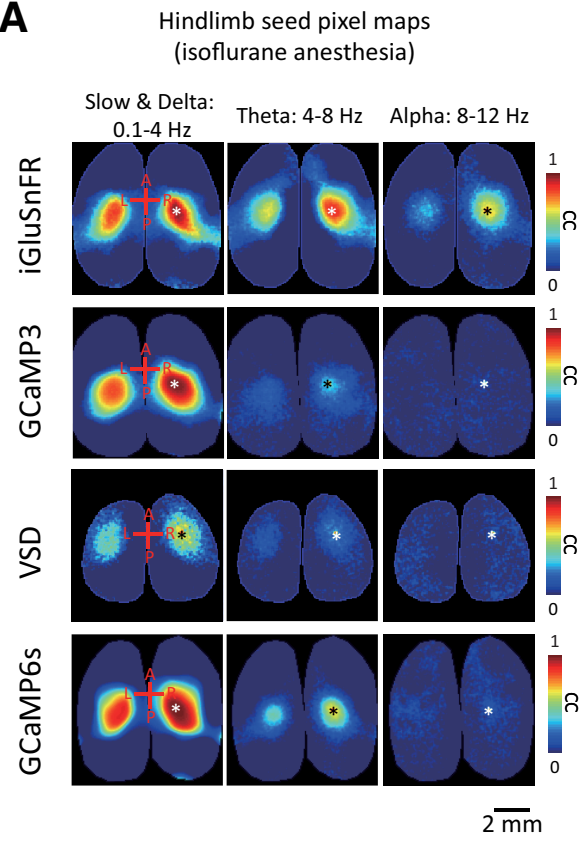

B

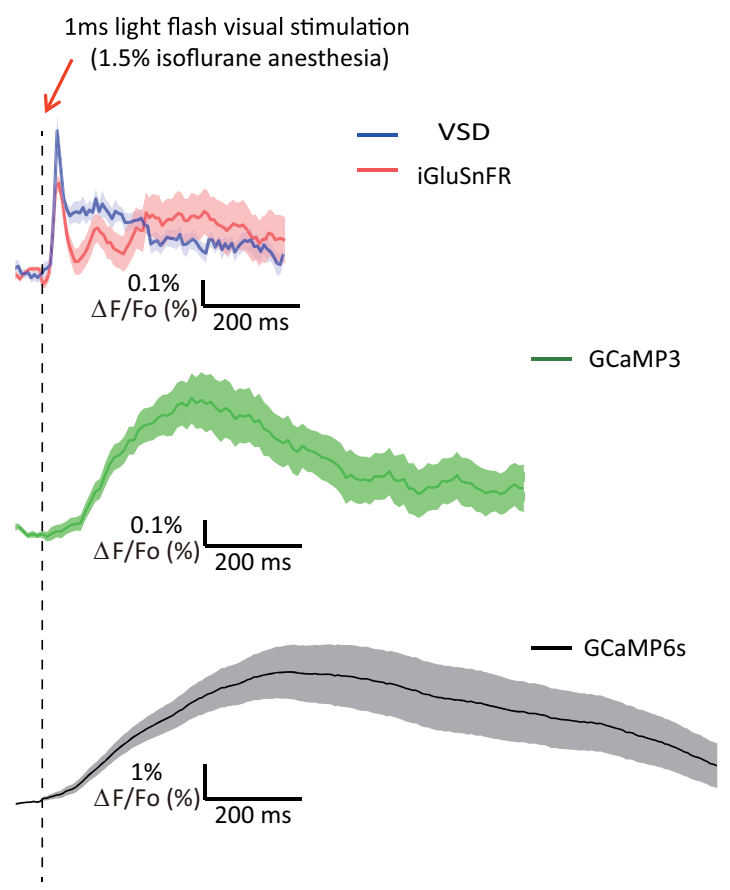

Figure 7. iGluSnFR is a fast regional activity reporter compared with other recombinant neuronal activity sensors. A, Comparison of seed-pixel correlation maps seeded within the hindlimb somatosensory cortex among various neuronal activity sensors within delta-, theta-, and alpha-frequency band indicates that iGluSnFR preserves the most high-frequency components for generating maps showing interhemispheric connections. All maps were generated from 20,000 frame sequences recorded at $150 \mathrm{~Hz}$ and were processed with global signal regression. Asterisks indicate seed locations. $\boldsymbol{B}$, Plot of the visual-stimulation-evoked responses measured from visual cortex showing rapid kinetics of iGluSnFR signals that are comparable to VSD signals and are faster than GCaMP3 and GCaMP6s. Representative traces are shown as mean \pm SEM of signals within V1 from the indicated sensors in individual animals (20 trials). 


\begin{tabular}{|c|c|c|c|c|}
\hline & $\Delta F / F(\%)$ & Time to peak (ms) & Decay $\tau_{1 / 2}(\mathrm{~ms})^{*}$ & SNR \\
\hline $\begin{array}{c}\text { Ai85 - iGluSnFR } \\
(n=11)\end{array}$ & $0.37 \pm 0.03$ & $67.55 \pm 6.54$ & $56.04 \pm 11.26$ & $44.69 \pm 6.11$ \\
\hline $\begin{array}{c}\text { RH1692 - VSD } \\
\quad(n=4)\end{array}$ & $0.47 \pm 0.07$ & $51.93 \pm 1.68$ & $26.80 \pm 6.12$ & $37.01 \pm 8.77$ \\
\hline $\begin{array}{c}\text { Ai38 - GCaMP3 } \\
(n=12)\end{array}$ & $0.42 \pm 0.05$ & $406.38 \pm 52.03$ & $207.42 \pm 19.78$ & $47.55 \pm 3.89$ \\
\hline $\begin{array}{c}\text { Aig4 - GCaMP6s } \\
(n=4)\end{array}$ & $2.72 \pm 0.38$ & $504.18 \pm 107.63$ & $495.80 \pm 100.24$ & $154.58 \pm 15.78$ \\
\hline
\end{tabular}

*The decay time reflects the time to $50 \%$ of peak amplitude, which for Ai85 and RH1692 occurred over the fast initial component of the response (see Figure $7 B$ ).

\section{Interpretation of iGluSnFR signals}

The signal from iGluSnFR likely reflects both the dynamics of glutamate release and clearance (Haustein et al., 2014). When changes are observed in regional iGluSnFR signals (or even at the cellular level), it is difficult to separate the contribution of release and reuptake. Potentially, the rapid rise time of the signals is more dependent on glutamate release and the decay period reflects unbinding, diffusion, and glutamate clearance by reuptake. Consistent with this, cellular imaging results have also shown that the blockade of reuptake lengthens iGluSnFR decay responses by approximately one order of magnitude (Marvin et al., 2013; Haustein et al., 2014). We observed amplified visual stimulationevoked regional iGluSnFR signals after the reduction in glutamate reuptake with $500 \mu \mathrm{M}$ TBOA. However, TBOA did not lengthen the decay time (Fig. $5 B$ ), suggesting a nuanced interpretation of the factors determining regional iGluSnFR signal kinetics in vivo. It is possible that reuptake is not a rate-limiting factor for the kinetics of visual responses from a glutamate perspective.

Using 2P imaging, we investigated the nature of wide-field iGluSnFR signals during spontaneous activity and after sensory stimulation (Fig. 6). This approach confirms a predominantly neuropil origin of iGluSnFR signals throughout the superficial cortical layers. Unfortunately, dense iGluSnFR expression in cortical excitatory neurons prevented identification of cellular iGluSnFR signals in Emx-CaMKII-iGluSnFR mice. The fluorescence is present in membrane compartments, making it difficult to resolve individual processes or somata. However, membrane localization is critical for monitoring extracellular glutamate. Membrane fluorescence contrasts with the relatively larger volumes that soluble probes such as GCaMPs occupy, making discrete somata relatively easy to resolve. When sparsely expressed, individual dendrites can be visualized using iGluSnFR imaging (Marvin et al., 2013); however, the probe is not selectively targeted and is expected to be present in both axonal and dendritic compartments (Marvin et al., 2013; Haustein et al., 2014). Future in vivo studies using sparse expression strategies will improve our understanding of local iGluSnFR signals.

\section{Comparison with other genetically encoded sensors for mesoscopic imaging}

Signal strength and kinetic properties of activity sensors are crucial for informative studies of event-related responses and cortical dynamics in vivo. We characterize these responses here using sensory-evoked responses and spontaneous brain activity. Various genetically encoded sensors have been developed (Akemann et al., 2010; Chen et al., 2013b; Huang and Zeng, 2013), but their usage in imaging at the mesoscopic level have not been carefully examined and compared. When tested in vitro, these recombi- nant glutamate sensors can have millisecond activation rates and $<100 \mathrm{~ms}$ decay kinetics. In addition to its specificity for glutamate signaling (Marvin et al., 2013), we found that iGluSnFR had the best kinetic properties for monitoring regional activity compared with other state-of-the-art genetically encoded sensors such as GCaMPs (Chen et al., 2013b; Vanni and Murphy, 2014; Madisen et al., 2015). This could be attributed to the fast clearance of extracellular glutamate, as well as the faster on and off rate of iGluSnFR compared with $\mathrm{Ca}^{2+}$ signaling and the kinetics of GCaMPs. Given that iGluSnFR reflects rapid excitatory neurotransmitter-related transmission, it may be suitable to the study of synaptic excitation/inhibition balance during wakefulness (Haider et al., 2013). Although visual responses to single flash stimuli offer the ability to extend imaging to awake animals (noncontact and less invasive), single brief stimuli directed to the whisker or limbs are likely best for evaluating the speed of processing.

\section{iGluSnFR can reveal frequency-dependent mesoscopic bilateral functional connectivity}

The seed-pixel correlation maps of iGluSnFR over $0.1-12 \mathrm{~Hz}$ were generally similar to what we found with GCaMP3 and VSD imaging using either $0.1-1 \mathrm{~Hz}$ or $0.5-6 \mathrm{~Hz}$ frequency spontaneous activity, respectively (Mohajerani et al., 2013; Vanni and Murphy, 2014). These spontaneous activity maps reflect structural connections within the cortex (Mohajerani et al., 2013; Oh et al., 2014) or areas receiving common upstream drive. Due to its rapid kinetics, we suggest that the regional activity of spontaneous iGluSnFR signals will be able to report bilateral homotopic functional connectivity that are associated with higher frequency events in particular in up to $12-30 \mathrm{~Hz}$ (Harris and Mrsic-Flogel, 2013; Mohajerani et al., 2013). Interestingly, although iGluSnFR may be able to assess functional connectivity in higher-frequency bands of activity, initial analysis suggests that long-distance functional connectivity can be well represented in $\sim 1 \mathrm{~Hz}$ activity. However, close inspection of maps reveals that mirrored homotopic maps may be less prevalent at $12-30 \mathrm{~Hz}$, indicating a frequency dependence to laterality (van Kerkoerle et al., 2014). The mesoscopic imaging of fast cortical iGluSnFR signals may assist monitoring information flow among cortical regions during behavior tasks (Matyas et al., 2010; Chen et al., 2013a; Guo et al., 2014b; Li et al., 2015). Consistent with this proposal, we readily observe both a primary and late secondary visual response (peaks at 200-250 ms) using iGluSnFR in vivo that may be related to intracortical reverberation of activity (Sachidhanandam et al., 2013; Funayama et al., 2015) in awake states.

\section{Signal processing considerations}

All of the single-wavelength GFP-based sensors, including GCa MPs and iGluSnFR, suffer from breathing-induced, heartbeat-induced, and hemodynamic artifacts (Hillman, 2007). Dual wavelength voltage-dependent Forster resonance energy transfer (FRET) sensors such as voltage-sensitive fluorescent proteinButterfly 1.2 or ratiometric Yellow Cameleon have the advantage to parse these other signals by applying signal equalization (Horikawa et al., 2010; Akemann et al., 2012), principal component analysis (Carandini et al., 2015), or other ratiometric methods (Minderer et al., 2012; Chen et al., 2013a). In our case, GSR (Aguirre et al., 1998; Fox et al., 2009) was applied to reduce global artifacts that may result from changes in blood volume and hemodynamic responses for GCaMP and iGluSnFR signals. However, we acknowledge that application of GSR could introduce artificial anticorrelation into the resting-state functional connectivity (Fox et al., 2009; Murphy et al., 2009) and removal of real 
global neuronal activity (Schölvinck et al., 2010). Therefore, interpretation of GSR-regressed data can require caution when slow signals and in particular when reductions in signal are evaluated (not the case for present work). Conversely, ratiometric optical signals of FRET-based glutamate sensors (Hires et al., 2008) may provide a convenient means to reduce movement and hemodynamic noise, but they have to be adapted to match the sensitivity of iGluSnFR (Marvin et al., 2013). Background signals due to flavoprotein autofluorescence, as previously proposed (Díez-García et al., 2007; Husson et al., 2007), and blood volume artifacts are unlikely to have contaminated iGluSnFR data significantly given that these artifacts are relatively slow and have been shown to minimally affect less sensitive and slower GCaMP3 signals (Vanni and Murphy, 2014). Control experiments (Vanni and Murphy, 2014) performed in wild-type nonfluorescent mice and activity-insensitive GFP mice (Feng et al., 2000) demonstrate that flavoprotein autofluorescence responses are much slower than iGluSnFR signals and only contribute to $<3 \%$ of the GFP responses in Emx-GCaMP3 mice. Signal fluctuations resulting from the absorption of the blue excitation light and green emission fluorescence by local hemoglobin concentration (estimated from GFP mice) was less pronounced compared with GCaMP3 signal (SD: 8\% relative to Emx-GCaMP3 spontaneous activity; Vanni and Murphy, 2014). Given that iGluSnFR signals are of comparable magnitude to GCaMP3 (but have faster kinetics), we expect these artifacts to contribute an even smaller percentage of variance to iGluSnFR signals.

In conclusion, longitudinal mesoscopic imaging of extracellular glutamate signals provides a new tool to monitor synaptic activity, with faster kinetics and neurotransmitter specificity, compared with other genetically encoded sensors such as GECIs. iGluSnFR has utility in normal physiology, as well as neurologic and psychiatric pathologies that are associated with glutamatergic abnormalities.

\section{References}

Aguirre GK, Zarahn E, D’Esposito M (1998) The inferential impact of global signal covariates in functional neuroimaging analyses. Neuroimage 8:302-306. CrossRef Medline

Akemann W, Mutoh H, Perron A, Rossier J, Knöpfel T (2010) Imaging brain electric signals with genetically targeted voltage-sensitive fluorescent proteins. Nat Methods 7:643-649. CrossRef Medline

Akemann W, Mutoh H, Perron A, Park YK, Iwamoto Y, Knöpfel T (2012) Imaging neural circuit dynamics with a voltage-sensitive fluorescent protein. J Neurophysiol 108:2323-2337. CrossRef Medline

Aschauer DF, Kreuz S, Rumpel S (2013) Analysis of transduction efficiency, tropism and axonal transport of AAV serotypes 1, 2, 5, 6, 8 and 9 in the mouse brain. PLoS One 8:e76310. CrossRef Medline

Bauer AQ, Kraft AW, Wright PW, Snyder AZ, Lee JM, Culver JP (2014) Optical imaging of disrupted functional connectivity following ischemic stroke in mice. Neuroimage 99:388-401. CrossRef Medline

Berger T, Borgdorff A, Crochet S, Neubauer FB, Lefort S, Fauvet B, Ferezou I, Carleton A, Lüscher HR, Petersen CC (2007) Combined voltage and calcium epifluorescence imaging in vitro and in vivo reveals subthreshold and suprathreshold dynamics of mouse barrel cortex. J Neurophysiol 97:3751-3762. CrossRef Medline

Bero AW, Bauer AQ, Stewart FR, White BR, Cirrito JR, Raichle ME, Culver JP, Holtzman DM (2012) Bidirectional relationship between functional connectivity and amyloid- $\beta$ deposition in mouse brain. J Neurosci 32: 4334-4340. CrossRef Medline

Carandini M, Shimaoka D, Rossi LF, Sato TK, Benucci A, Knöpfel T (2015) Imaging the awake visual cortex with a genetically encoded voltage indicator. J Neurosci 35:53-63. CrossRef Medline

Chan AW, Mohajerani MH, LeDue JM, Wang YT, Murphy TH (2015) Mesoscale infraslow spontaneous membrane potential fluctuations recapitulate high-frequency activity cortical motifs. Nat Commun 6:7738. Medline
Chen JL, Carta S, Soldado-Magraner J, Schneider BL, Helmchen F (2013a) Behaviour-dependent recruitment of long-range projection neurons in somatosensory cortex. Nature 499:336-340. CrossRef Medline

Chen TW, Wardill TJ, Sun Y, Pulver SR, Renninger SL, Baohan A, Schreiter ER, Kerr RA, Orger MB, Jayaraman V, Looger LL, Svoboda K, Kim DS (2013b) Ultrasensitive fluorescent proteins for imaging neuronal activity. Nature 499:295-300. CrossRef Medline

Díez-García J, Akemann W, Knöpfel T (2007) In vivo calcium imaging from genetically specified target cells in mouse cerebellum. Neuroimage 34: 859-869. CrossRef Medline

Feng G, Mellor RH, Bernstein M, Keller-Peck C, Nguyen QT, Wallace M, Nerbonne JM, Lichtman JW, Sanes JR (2000) Imaging neuronal subsets in transgenic mice expressing multiple spectral variants of GFP. Neuron 28:41-51. CrossRef Medline

Ferezou I, Haiss F, Gentet LJ, Aronoff R, Weber B, Petersen CC (2007) Spatiotemporal dynamics of cortical sensorimotor integration in behaving mice. Neuron 56:907-923. CrossRef Medline

Fox MD, Zhang D, Snyder AZ, Raichle ME (2009) The global signal and observed anticorrelated resting state brain networks. J Neurophysiol 101: 3270-3283. CrossRef Medline

Funayama K, Minamisawa G, Matsumoto N, Ban H, Chan AW, Matsuki N, Murphy TH, Ikegaya Y (2015) Neocortical rebound depolarization enhances visual perception. PLoS Biol 13:e1002231. CrossRef Medline

Gorski JA, Talley T, Qiu M, Puelles L, Rubenstein JL, Jones KR (2002) Cortical excitatory neurons and glia, but not GABAergic neurons, are produced in the Emx1-expressing lineage. J Neurosci 22:6309-6314. Medline

Grinvald A, Hildesheim R (2004) VSDI: a new era in functional imaging of cortical dynamics. Nat Rev Neurosci 5:874-885. CrossRef Medline

Grynkiewicz G, Poenie M, Tsien RY (1985) A new generation of Ca2+ indicators with greatly improved fluorescence properties. J Biol Chem 260: 3440-3450. Medline

Guo ZV, Hires SA, Li N, O’Connor DH, Komiyama T, Ophir E, Huber D, Bonardi C, Morandell K, Gutnisky D, Peron S, Xu NL, Cox J, Svoboda K (2014b) Procedures for behavioral experiments in head-fixed mice. PLoS One 9:e88678. CrossRef Medline

Guo ZV, Li N, Huber D, Ophir E, Gutnisky D, Ting JT, Feng G, Svoboda K (2014a) Flow of cortical activity underlying a tactile decision in mice. Neuron 81:179-194. CrossRef Medline

Haider B, Häusser M, Carandini M (2013) Inhibition dominates sensory responses in the awake cortex. Nature 493:97-100. Medline

Harris KD, Mrsic-Flogel TD (2013) Cortical connectivity and sensory coding. Nature 503:51-58. CrossRef Medline

Haustein MD, Kracun S, Lu XH, Shih T, Jackson-Weaver O, Tong X, Xu J, Yang XW, O’Dell TJ, Marvin JS, Ellisman MH, Bushong EA, Looger LL, Khakh BS (2014) Conditions and constraints for astrocyte calcium signaling in the hippocampal mossy fiber pathway. Neuron 82:413-429. CrossRef Medline

Hillman EM (2007) Optical brain imaging in vivo: techniques and applications from animal to man. J Biomed Opt 12:051402. Medline

Hires SA, Zhu Y, Tsien RY (2008) Optical measurement of synaptic glutamate spillover and reuptake by linker optimized glutamate-sensitive fluorescent reporters. Proc Natl Acad Sci U S A 105:4411-4416. CrossRef Medline

Horikawa K, Yamada Y, Matsuda T, Kobayashi K, Hashimoto M, Matsu-ura T, Miyawaki A, Michikawa T, Mikoshiba K, Nagai T (2010) Spontaneous network activity visualized by ultrasensitive $\mathrm{Ca}(2+)$ indicators, yellow Cameleon-Nano. Nat Methods 7:729-732. CrossRef Medline

Huang ZJ, Zeng H (2013) Genetic approaches to neural circuits in the mouse. Annu Rev Neurosci 36:183-215. CrossRef Medline

Huber D, Gutnisky DA, Peron S, O'Connor DH, Wiegert JS, Tian L, Oertner TG, Looger LL, Svoboda K (2012) Multiple dynamic representations in the motor cortex during sensorimotor learning. Nature 484:473-478. CrossRef Medline

Hunnicutt BJ, Long BR, Kusefoglu D, Gertz KJ, Zhong H, Mao T (2014) A comprehensive thalamocortical projection map at the mesoscopic level. Nat Neurosci 17:1276-1285. CrossRef Medline

Husson TR, Mallik AK, Zhang JX, Issa NP (2007) Functional imaging of primary visual cortex using flavoprotein autofluorescence. J Neurosci 27:8665-8675. CrossRef Medline

Knöpfel T, Díez-García J, Akemann W (2006) Optical probing of neuronal circuit dynamics: Genetically encoded versus classical fluorescent sensors. Trends Neurosci 29:160-166. CrossRef Medline 
Li N, Chen TW, Guo ZV, Gerfen CR, Svoboda K (2015) A motor cortex circuit for motor planning and movement. Nature 519:51-56. CrossRef Medline

Madisen L, Garner AR, Shimaoka D, Chuong AS, Klapoetke NC, Li L, van der Bourg A, Niino Y, Egolf L, Monetti C, Gu H, Mills M, Cheng A, Tasic B, Nguyen TN, Sunkin SM, Benucci A, Nagy A, Miyawaki A, Helmchen F, Empson RM, Knöpfel T, Boyden ES, Reid RC, Carandini M, Zeng H (2015) Transgenic mice for intersectional targeting of neural sensors and effectors with high specificity and performance. Neuron 85:942-958. CrossRef Medline

Marvin JS, Borghuis BG, Tian L, Cichon J, Harnett MT, Akerboom J, Gordus A, Renninger SL, Chen TW, Bargmann CI, Orger MB, Schreiter ER, Demb JB, Gan WB, Hires SA, Looger LL (2013) An optimized fluorescent probe for visualizing glutamate neurotransmission. Nat Methods 10:162-170. CrossRef Medline

Matyas F, Sreenivasan V, Marbach F, Wacongne C, Barsy B, Mateo C, Aronoff R, Petersen CC (2010) Motor control by sensory cortex. Science 330: 1240-1243. CrossRef Medline

Mayford M, Bach ME, Huang YY, Wang L, Hawkins RD, Kandel ER (1996) Control of memory formation through regulated expression of a CaMKII transgene. Science 274:1678-1683. CrossRef Medline

Minderer M, Liu W, Sumanovski LT, Kügler S, Helmchen F, Margolis DJ (2012) Chronic imaging of cortical sensory map dynamics using a genetically encoded calcium indicator. J Physiol 590:99-107. CrossRef Medline

Mohajerani MH, McVea DA, Fingas M, Murphy TH (2010) Mirrored bilateral slow-wave cortical activity within local circuits revealed by fast bihemispheric voltage-sensitive dye imaging in anesthetized and awake mice. J Neurosci 30:3745-3751. CrossRef Medline

Mohajerani MH, Chan AW, Mohsenvand M, LeDue J, Liu R, McVea DA, Boyd JD, Wang YT, Reimers M, Murphy TH (2013) Spontaneous cortical activity alternates between motifs defined by regional axonal projections. Nat Neurosci 16:1426-1435. CrossRef Medline

Murphy K, Birn RM, Handwerker DA, Jones TB, Bandettini PA (2009) The impact of global signal regression on resting state correlations: are anticorrelated networks introduced? Neuroimage 44:893-905. CrossRef Medline

Oh SW, Harris JA, Ng L, Winslow B, Cain N, Mihalas S, Wang Q, Lau C, Kuan L, Henry AM, Mortrud MT, Ouellette B, Nguyen TN, Sorensen SA, Slaughterbeck CR, Wakeman W, Li Y, Feng D, Ho A, Nicholas E, Hirokawa KE, Bohn P, Joines KM, Peng H, Hawrylycz MJ, Phillips JW, Hohmann JG, Wohnoutka P, Gerfen CR, Koch C, Bernard A, Dang C, Jones AR, Zeng H (2014) A mesoscale connectome of the mouse brain. Nature 508:207-214. CrossRef Medline

Okubo Y, Sekiya H, Namiki S, Sakamoto H, Iinuma S, Yamasaki M, Watanabe M, Hirose K, Iino M (2010) Imaging extrasynaptic glutamate dynamics in the brain. Proc Natl Acad Sci US A 107:6526-6531. CrossRef Medline

Petersen CC, Grinvald A, Sakmann B (2003) Spatiotemporal dynamics of sensory responses in layer $2 / 3$ of rat barrel cortex measured in vivo by voltage-sensitive dye imaging combined with whole-cell voltage recordings and neuron reconstructions. J Neurosci 23:1298-1309. Medline

Rose T, Goltstein PM, Portugues R, Griesbeck O (2014) Putting a finishing touch on GECIs. Front Mol Neurosci 7:88. Medline

Sachidhanandam S, Sreenivasan V, Kyriakatos A, Kremer Y, Petersen CC (2013) Membrane potential correlates of sensory perception in mouse barrel cortex. Nat Neurosci 16:1671-1677. CrossRef Medline

Schölvinck ML, Maier A, Ye FQ, Duyn JH, Leopold DA (2010) Neural basis of global resting-state fMRI activity. Proc Natl Acad Sci U S A 107:1023810243. CrossRef Medline
Shimamoto K, Lebrun B, Yasuda-Kamatani Y, Sakaitani M, Shigeri Y, Yumoto N, Nakajima T (1998) DL-threo-beta-benzyloxyaspartate, a potent blocker of excitatory amino acid transporters. Mol Pharmacol 53: 195-201. Medline

Shoham D, Glaser DE, Arieli A, Kenet T, Wijnbergen C, Toledo Y, Hildesheim R, Grinvald A (1999) Imaging cortical dynamics at high spatial and temporal resolution with novel blue voltage-sensitive dyes. Neuron 24:791-802. CrossRef Medline

Silasi G, Murphy TH (2014) Stroke and the connectome: how connectivity guides therapeutic intervention. Neuron 83:1354-1368. CrossRef Medline

Silasi G, Boyd JD, Ledue J, Murphy TH (2013) Improved methods for chronic light-based motor mapping in mice: automated movement tracking with accelerometers, and chronic EEG recording in a bilateral thinskull preparation. Front Neural Circuits 7:123. Medline

Stroh A, Adelsberger H, Groh A, Rühlmann C, Fischer S, Schierloh A, Deisseroth K, Konnerth A (2013) Making waves: initiation and propagation of corticothalamic Ca2 + waves in vivo. Neuron 77:1136-1150. CrossRef Medline

Tian L, Hires SA, Mao T, Huber D, Chiappe ME, Chalasani SH, Petreanu L, Akerboom J, McKinney SA, Schreiter ER, Bargmann CI, Jayaraman V, Svoboda K, Looger LL (2009) Imaging neural activity in worms, flies and mice with improved GCaMP calcium indicators. Nat Methods 6: 875-881. CrossRef Medline

Tian L, Hires SA, Looger LL (2012) Imaging neuronal activity with genetically encoded calcium indicators. Cold Spring Harb Protoc 2012: 647-656. Medline

van den Heuvel MP, Hulshoff Pol HE (2010) Exploring the brain network: a review on resting-state fMRI functional connectivity. Eur Neuropsychopharmacol 20:519-534. CrossRef Medline

van Kerkoerle T, Self MW, Dagnino B, Gariel-Mathis MA, Poort J, van der Togt C, Roelfsema PR (2014) Alpha and gamma oscillations characterize feedback and feed-forward processing in monkey visual cortex. Proc Natl Acad Sci U S A 111:14332-14341. CrossRef Medline

van Drongelen W (2007) Signal processing for neuroscientists. Burlington, MA: Elsevier.

Vanni MP, Murphy TH (2014) Mesoscale Transcranial spontaneous activity mapping in GCaMP3 transgenic mice reveals extensive reciprocal connections between areas of somatomotor cortex. J Neurosci 34:1593115946. CrossRef Medline

White BR, Bauer AQ, Snyder AZ, Schlaggar BL, Lee JM, Culver JP (2011) Imaging of functional connectivity in the mouse brain. PLoS One 6:e16322. CrossRef Medline

Xie Y, Chen S, Murphy T (2012) Dendritic spines and pre-synaptic boutons are stable despite local deep hypothermic challenge and re-warming in vivo. PLoS One 7:e36305. CrossRef Medline

Xie Y, Chen S, Wu Y, Murphy TH (2014) Prolonged deficits in parvalbumin neuron stimulation-evoked network activity despite recovery of dendritic structure and excitability in the somatosensory cortex following global ischemia in mice. J Neurosci 34:14890-14900. CrossRef Medline

Zariwala HA, Borghuis BG, Hoogland TM, Madisen L, Tian L, De Zeeuw CI, Zeng H, Looger LL, Svoboda K, Chen TW (2012) A Cre-dependent GCaMP3 reporter mouse for neuronal imaging in vivo. J Neurosci 32: 3131-3141. CrossRef Medline

Zhang D, Raichle ME (2010) Disease and the brain's dark energy. Nat Rev Neurol 6:15-28. CrossRef Medline

Zingg B, Hintiryan H, Gou L, Song MY, Bay M, Bienkowski MS, Foster NN, Yamashita S, Bowman I, Toga AW, Dong HW (2014) Neural networks of the mouse neocortex. Cell 156:1096-1111. CrossRef Medline 